\title{
Direct and Interaction Effects of Cognitive Bias and Anxiety on Credit Misuse among
} U.S. College Students

Sun Young Ahn ${ }^{1} \cdot$ Ya-Hui Kuo ${ }^{2} \cdot$ Joyce Serido $^{3}$. Soyeon Shim ${ }^{4}$

${ }^{1}$ Business Management, Washington College, Visiting Assistant Professor, ${ }^{2}$ Institute of International Business, National Cheng Kung University, Assistant Professor, ${ }^{3}$ Family Social Science, University of Minnesota, Associate Professor, ${ }^{4}$ School of Human Ecology, University of Wisconsin-Madison, Professor

\section{인지적 편향과 불안감이 미국 대학생의 위험 신용 행동에 미치는 영향과상호작용효과}

안선영 ${ }^{1} \cdot \mathrm{Ya}-\mathrm{Hui} \mathrm{Kuo}^{2} \cdot$ Joyce Serido $^{3}$. 심소연 ${ }^{4}$

${ }^{1}$ 미국 워싱턴 컬리지 경영학과 객원조교수, ${ }^{2}$ 대만 국립 성공 대학교 국제 비지니스 조교수,

${ }^{3}$ 미국 미네소타 대학교 가족사회학과 부교수, ${ }^{4}$ 미국 위스콘신 대학교 매디슨 생활과학대학 교수

\section{Family and}

\section{Environment}

\section{Research}

Received: September 14, 2018

Revised: October 4, 2018

Accepted: October 4, 2018

An earlier version of this article was presented at the American Council on Consumer Interests (ACCI) Annual Conference, Portland, OR, U.S., April, 2013

\section{Corresponding Author:} Sun Young Ahn

Business Management, Washington College, 300 Washington Avenue, Chestertown, MD, U.S.

Tel: $+1-410-810-5086$

Fax: +1-410-810-7170

E-mail:sahn2@washcoll.edu

\section{Abstract}

This study determines whether certain cognitive biases (i.e., time preference, goal attainment expectation, unrealistic optimism, and overconfidence) and a specific negative mood-state (i.e., anxiety) influence credit misuse among college students. Data were collected from fourth-year college students $(N=1,146)$, all of whom attended the same university in the southwest United States. Hierarchical multiple regression analyses and moderator analyses were employed to test the research hypotheses. Results showed that specific cognitive biases and anxiety were directly associated with credit misuse. We found that the longer goal attainment was delayed, the greater the students' unrealistic optimism concerning future income; in addition, the more overconfident they became with respect to financial knowledge, the more frequently they engaged in credit misuse. The study also showed that the higher a student's level of anxiety, the more often that students engaged in credit misuse. We also found that cognitive bias factors and anxiety interact to influence credit misuse. Anxiety interacted with time preference and unrealistic optimism such that present-oriented time preference was negatively related to credit misuse while optimism toward future income was positively related to credit misuse, but only for students with high anxiety levels. The findings of this study are discussed in the context of understanding and preventing irresponsible financial behavior among young adults.

\section{Keywords}

anxiety, cognitive bias, college students, credit misuse

\section{Introduction}

A college degree is a significant investment in the financial future, an investment that often requires debt-financing. Although high student loan debt has been linked to higher rates of stress (Stein et al., 2013), increased financial anxiety, lower levels of physical and psychological well-being (Archuleta, Dale \& Spann, 2013; Sweet et al., 2013), and an unwillingness to borrow can negatively influence degree completion (Museus, 2010). Although prudent borrowing may foster degree completion (Price \& Davis, 2006), misuse of credit may result in excessive debt. It is therefore important to understand the factors 
that may interfere with prudent borrowing. The rising costs of higher education ( $\mathrm{Ma} \&$ Baum, 2016) has contributed to a generation burdened by debt (Houle, 2014). Excessive debt among college students has been linked to credit card behaviors (Xiao et al., 2011). Robb and Pinto (2010) found that financially at-risk students used credit cards with greater frequency and engaged in riskier credit card use behaviors. Literature showed a high association among different types of debt (i.e., student loan, credit card debt, auto loans, and installment debt) among college students (Archuleta, Dale \& Spann, 2013) suggesting that some set of factors or processes may be common to explain debt borrowing behaviors for college students regardless of the type of debt. Credit misuse is defined as behaviors that negatively impact credit score (e.g., missed payments, maxing out credit limits, use of payday loan service or cash advance). Credit misuse, therefore, is an appropriate topic of financial behavior of college students to understand factors to explain poor financial decisions.

The extant research has identified several factors associated with college students' irresponsible borrowing behavior or credit misuse, including sociodemographic (e.g., gender, ethnicity, and social class) (e.g., Lusardi, Mitchell, \& Curto, 2010; Lyons, 2008), financial knowledge and attitudes (Davies \& Lea, 1995; Norvilitis et al., 2006), personal characteristic (e.g., self-esteem, power-prestige, and social motivation) (Limbu, 2017; Palan et al., 2011), and parental socialization (e.g., Gudmunson \& Danes 2011; Shim et al., 2010). However, in identifying factors associated with an increased credit misuse, more recent studies suggest that personal financial behavior cannot be understood solely as a rational process, instead the process must be given a more realistic psychological foundation (Smith et al., 2015; Wilkinson, 2008). A behavioral economic perspective combines psychology and economics to investigate decision-making patterns inconsistent with an assumption of rationality (Camerer et al., 2003). The concept of 'bounded rationality’ (Simon, 1972) explains irrationality by referencing decision-making that is influenced by personal attributes including overconfidence, personal need, desire, and inadequate skills (Smith et al., 2015). Applying these patterns might well show us that irresponsible financial behavior researchers have catalogued results from irrational decisions. In this study, thus, we conceptualize credit misuse as a form of irrational financial decision-making.

In the realm of behavioral economics, certain cognitive biases have long been considered factors that contribute to irrational decision-making. Cognitive bias, an unrealistically positive self-perception about one's capabilities (Weinstein, 1980), promotes the use of abbreviated decision-making methods to reach a decision more quickly than usual (Haselton, Nettle \& Andrews, 2005). Cognitive bias suggests an individual draws on an inference even though "the evidence for doing so in a logically sound manner is either insufficient or absent" (Haselton, Nettle \& Andrews, 2005). In these instances, people may weigh the costto-benefit ratio differently. Based on literature, we focus on four bias factors that are prevalent among and reflective of students' limited experience with borrowing and debt: time preference, goal attainment expectations, unrealistic optimism, and overconfidence. Time preference or present bias to prefer indulging today to gain immediate gratification, will contribute to more risky or irrational decision-making (e.g., Finke \& Huston, 2003). Overconfidence (e.g., overestimating one's knowledge) has been associated with individual misjudgments related to personal limitations and, consequently, with inferior personal decisions (e.g., Alba \& Hutchinson, 2000). Likewise, goal attainment expectation, defined as the extent to which a person believes he or she will achieve a goal is also associated with behavioral outcomes (e.g., Jones, 1995). Finally, unrealistic optimism about future income has also been found to encourage people to take on greater debt (Norvilitis et al., 2006). In light of these findings, it would seem reasonable to assume that young adults, being subject to all of these irrational biases, will make decisions that are not in their own best interest. And it also would seem reasonable that establishing a link between such factors and credit misuse among young adults would help those who 
want to develop measures to counteract the increasing rise in student debt. Yet few studies have sought to establish such an association.

Cognitive biases may not be the only factors that contribute to irrational decision-making. Certain negative mood-states might also interfere with individual decisionmaking. Negative mood might also interfere with prudent financial decision-making (Isen \& Means, 1983). Previous studies, for example, have found that negative mood adversely affects a person's decision-making ability regarding stock investment, gambling, and buying lottery tickets (e.g., Gambetti \& Giusberti, 2012; Leith \& Baumeister 1996). Many college students are graduating with fewer job prospects (Shierholz, Sabadish, \& Finio, 2013) which may contribute to a feeling of financial anxiety. Thus, the present study considers if financial anxiety affects credit misuse among college students.

Because excessive debt undermines students' financial and personal well-being (Vlaev \& Elliott, 2013), the goal of this study is to apply a behavioral economics perspective to examine the associations of cognitive bias and anxiety on credit misuse. This study offers contributions to both academic and practitioner knowledge. The current study provides additional understanding of college students' financial behavior by simultaneously considering the role of both cognitive bias factors and anxiety. Our findings also help financial educators, practitioners, and parents to guide college students for better finance management and financial well-being.

\section{Literature Review and Hypotheses Development}

\section{Time Preference and Credit Misuse}

Time preference refers to a tendency to prefer immediate utility over delayed utility (Frederick, Loewenstein, \& O’ Donoghue, 2002). A person with a present-oriented focus has a preference to satisfy a desire immediately rather than to delay that satisfaction (Finke \& Huston, 2003). If a particular behavior has upfront benefits and delayed costs (e.g., using cash advance from a credit card now and paying back later), an individual might place greater value on the present pleasure and a lower value on the future cost. Thus, individuals with a present-time bias would be more likely to engage in credit misuse, thereby risking future well-being. Previous studies have shown positive associations between time preference and irrational behaviors. In financial domains, studies have found that present-time bias was related to higher credit card debt (e.g., Lea, Webley, \& Walker, 1995; Meier \& Sprenger, 2010). We use the term "present-oriented time preference" to refer to this tendency to focus on the present rather than a future period of time with respect to financial planning and hypothesized that:

Hypothesis 1: Students with a more present-oriented time preference toward financial planning will engage in more credit misuse.

\section{Goal Attainment Expectations and Credit Misuse}

Financial planning depends on a willingness to put off gratification and accept delays in achieving financial goals, similar to the cognitive bias of procrastination (O’Donoghue \& Rabin, 2001a). Generally, goal attainment expectation is defined as the extent to which people think they will achieve a goal (i.e., definitely yes to definitely no) (Jones \& Hanton, 1996). Individuals who have positive expectations about achieving goals interpret environmental factors as supportive of their goals, which in turn promotes behavior consistent with attaining those goals (Jones, 1995). Although financial independence is an important goal among college students (Arnett, 2004), most have not yet achieved it (Mulder \& Clark, 2002). The present study defines goal attainment expectation in terms of temporal expectation, that is, the expected time to achieve financial independence (e.g., less than five years). It is possible that students who expect to take a long time (e.g., more than ten years) to attain financial independence may be more willing to misuse credit compared to those who expect to achieve financial independence sooner (e.g., less than five years). Consequently, we hypothesized that: 
Hypothesis 2: Students expecting to wait longer to attain financial independence will be more likely to engage in more credit misuse.

\section{Unrealistic Optimism and Credit Misuse}

In general, unrealistic optimism is the tendency to be overly optimistic about one's future fate or future behavior (Price, 2000). Several empirical studies have examined the association between unrealistic optimism and personal finances. For instance, Yang and Gysbers (2007) found that consumers who were overly optimistic about their future credit borrowing behavior were more likely to prefer credit cards with higher interest rates. Studies also suggested that unrealistic optimism may account for consumers' tendency to overestimate their ability to repay (Exler et al., 2018; Sunstein, 2006). Although individuals in general tend to be unrealistically optimistic about future events (O’Donoghue \& Rabin, 2001b), excessive optimism is more prominent among college students (Weinstein, 1980). Further, unrealistic optimism with respect to future income has been found to be a significant predictor of credit card debt (Norvilitis et al., 2006) and student loans (Seaward \& Kemp, 2000). From this perspective, unrealistic optimism can lead to biased decision-making, and in turn promote more credit misuse. We operationalize the "unrealistic optimism" in terms of students' anticipated future income level, and use it to explain credit misuse. Consequently, we hypothesized that:

Hypothesis 3: Students who anticipate a higher future income will be more likely to engage in credit misuse.

\section{Overconfidence and Credit Misuse}

Overconfidence, the tendency to overestimate one' s own understanding, or knowledge (Gervais, Heaton, \& Odean, 2002), may contribute to credit misuse. Previous research has shown that individuals tend to overestimate their knowledge or ability relative to objective assessments which may have a negative effect on behavior (Perry, 2008). Thus, consumers may not assess their knowledge accurately reflecting a discrepancy between their objective and subjective knowledge (Alba \& Hutchinson, 2000). For our purposes, we define overconfidence as the gap between individual subjective knowledge and assessed objective financial knowledge. We assess objective financial knowledge by a content knowledge test score and subjective knowledge as self-assessed understanding of content knowledge. Overconfident individuals may not recognize and may make insufficient adjustments in response to such recognition (Hirshleifer, 2008). Thus, overconfidence may account for biased decision-making (Alba \& Hutchinson, 2000) and more poor financial decisions. For instance, a study by Perry (2008) found that consumers who overestimated their credit ratings were less likely to engage in prudent financial behavior. Studies also empirically supported that overconfidence in one's financial knowledge lowers the probability to pay off credit card debt (Peach \& Yuan, 2017) and increases risky financial behaviors (Tokar Asaad, 2015). Although financial knowledge has been studied as a factor contributing to prudent financial behavior (e.g., Shim et al., 2010), little research has directly examined the relation between accurate self-assessment of financial knowledge and borrowing behavior. Given these findings, we hypothesized that:

Hypothesis 4: Students who are overconfident about their financial knowledge will engage in more credit misuse.

\section{Anxiety and Credit Misuse}

The mood-maintenance hypothesis (Isen \& Patrick, 1983) suggests that people experiencing negative affect increasingly take greater risks in the hope of acquiring higher gains and thereby improving their affective state. Overall, negative mood-states have been found to be associated with less deliberate (Isen \& Means, 1983) and more risky (Dunegan, Duchon, \& Barton, 1992) decisionmaking. As students prepare for full-time adult roles and responsibilities, some may feel more anxious about their future (Barnett et al., 2003). Consequently, anxiety might impair their ability to make sound financial decisions, especially those made on a daily basis. Leith and Baumeister (1996) found that anxiety promoted more risky choices while gambling and thus provide some empirical support 
for this association. Based on both theoretical and empirical support, we hypothesized as follows:

Hypothesis 5: Students who are more anxious will engage in more credit misuse.

\section{Interactions Between Cognitive Bias and Anxiety}

Anxiety may exert its influence on decision making by altering cognitive processes with interpretative biases (Barlow, 2002), thus it is plausible that both factors might combine to interfere with decision-making. Gray and colleagues (2002) found that anxiety impaired cognitive processing (e.g., memory). Further, Bishop (2008) found that highly anxious subjects took longer to identify targets associated with given tasks. Although these studies examined subjects engaged in a general cognitive task, the findings suggest a possible interaction effect between anxiety and cognitive factors. Thus, we hypothesized that:

Hypothesis 6: Cognitive bias factors will interact with anxiety such that the relationship between cognitive bias factors and credit misuse will be stronger with a higher level of anxiety.

\section{Method}

\section{Procedure and Participants}

The data was collected as part of a longitudinal study investigating financial behavior development of young adults. After receiving IRB approval, surveys were administered at two time points (T1 and T2) to a sample of college students. The T1 survey was administered in spring 2008 (i.e., first year of college). The T2 survey was administered in fall 2010 (i.e., fourth year of college). The present study uses T2 data from the students who participated in both waves and possessed at least one credit card $(N=1,146)$. All participants received a nominal financial incentive for completing the survey. The study sample was comprised of more females (64\%) than males (36\%). The ethnic composition of the sample was predominantly White (68.7\%), followed by Hispanic (14.2\%), Asian (9.6\%), Black
(3.6\%) and other/missing (3.9\%). The average self-reported GPA was 3.33.

\section{Measures}

Credit misuse. Derived from previous research (Lyons, 2004), participants were asked to indicate, on a scale ranging from 1 (never) to 5 (very often), how often within the past six-months they engaged in four credit misuse behaviors (e.g., took cash advance from credit card; used payday loan service; maxed out credit card limit; paid credit card bill on time each month (reverse coded)). Higher scores indicated more misuse of credit $(\alpha=.63)$.

Time preference. Time preference is operationalized as time preference with respect to financial planning. Adopted from previous research (Lusardi, 1998), participants were asked to indicate what time period, from 1 (next month) to 6 (longer than 10 years), they believed was most important when planning their finances. The item was reverse coded so that higher scores represented present-orientation bias and lower scores represented future bias.

Goal attainment expectation. Based on previous studies (e.g., Jones \& Hanton, 1996), the current study operationalized the goal attainment expectation as temporal expectation to achieve financial independence. Participants were asked to indicate, on a scale ranging from 1 (within 5 years) to 5 (not likely to achieve), when they thought they would achieve financial independence. The higher score indicated a longer expected delay to achieve financial independence.

Unrealistic optimism. Students' anticipated future income was used to measure unrealistic optimism. Adopted from previous research (Seaward \& Kemp, 2000), participants were asked to indicate how much they expected to be earning annually five years after graduation. The range was $\$ 17,000$ to $\$ 1,000,000$, with an average of $\$ 71,179$. We recoded the value of future income using a four-point scale: 1(lowest -\$45,000;25.2\%), 2(\$45,000 -\$60,000;29.4\%), $3(\$ 60,000-\$ 75,000 ; 18.8 \%)$, and 4 (over $\$ 75,000-; 26.6 \%)$.

Overconfidence. Overconfidence was measured as the difference between a student's subjective knowledge and 
objective knowledge regarding several financial topics. Subjective financial knowledge was measured by asking participants to rate the degree to which they understood seven financial concepts (e.g., interpretation on credit reports, return rate of saving bonds) on a 5-point scale ranging from 1 (very little) to 5 (quite a lot). A higher score represented a higher level of subjective financial knowledge $(\alpha=.88)$. Objective knowledge was initially computed as the percentage of correct answers out of 15 True/False questions related to the understanding of money management, credit, and saving (Hilgert, Hogarth \& Beverly, 2003) (e.g., making payments late on your bills can make getting a loan more difficult). For this study, percentage scores were classified into 5 levels, ranging from 1 (0 to 20\%) to 5 (80\% to $100 \%$ ), with a higher level indicating higher objective financial knowledge. We subtracted the level of objective knowledge from the level of subjective financial knowledge (possible range: -4 to 4 ) with a positive score representing overconfidence about financial knowledge. The majority of students (87.4\%) underestimated their financial knowledge, 7.6\% overestimated their financial knowledge, and $4.2 \%$ correctly assessed their financial knowledge.

Anxiety. Anxiety was measured by asking participants to indicate, on a 5-point scale ranging from 1 (never) to 5 (daily), how frequently they experienced each of four concerns (e.g., worry that you may not have enough money to pay for things; worry that you won't get a good job in the future) (Barber, Eccles \& Stone, 2001). Higher scores indicated higher levels of anxiety $(\alpha=.71)$.

Control variables. All analyses controlled for gender (0 =male; 1 =female), current academic achievement (selfreported GPA) and parental socio-economic status (SES). As previous studies have shown, parental SES influences an individual's levels of financial knowledge and behavior (i.e., Lyons, Rachilis, \& Scherpf, 2007). SES (Coleman, 1983) was measured as a summation of father's and mother' s education level of ( $1=$ less than high school to $5=$ graduate school or professional degree) and parental income (1=less than $\$ 50,000$ to $4=$ more than $\$ 200,000)$ ).

\section{Plan of Analyses}

Hierarchical multiple regression was used to first assess the separate and direct associations of cognitive bias and anxiety on credit misuse, and then to examine the interaction of cognitive bias factors and anxiety on credit misuse. To test the interaction between cognitive bias and anxiety, we included a separate interaction term, computed as the product of each of the four cognitive bias factors and anxiety (e.g., time preference $\mathrm{x}$ anxiety) as the last step in the regression equation (Baron \& Kenny 1986). All predictors were mean-centered with $\mathrm{z}$-scores to interpret the simple effects and to reduce multicollinearity between predictors and the moderator (Jaccard \& Turrisi, 2003). An incremental $\mathrm{F}$ test assessed whether the product term added predictability over the account provided by the model using only the factors of cognitive bias and anxiety.

\section{Results}

\section{Descriptive Results}

The means, standard deviations, and correlations among the study variables are presented in Table 1 . The descriptive statistics and the frequency distribution for each item of credit misuse scale is presented in Table 2. All correlations were significant at the .05 level. The intercorrelations showed, first, that the cognitive bias factors were significant but weakly correlated. Time preference was correlated with less goal attainment expectation $(r=-.08)$ and less unrealistic optimism regarding future income $(r=-$ .08). Overconfidence was negatively correlated with goal attainment expectation $(r=-.09)$ and positively correlated with unrealistic optimism $(r=.16)$. Second, we found weak and inconsistent correlations among cognitive bias factors and anxiety. Anxiety was positively correlated with delayed goal attainment expectation $(r=.16)$ but negatively correlated with unrealistic optimism $(r=-$.11). Finally, credit misuse was related to three of the cognitive factors and anxiety in the hypothesized direction. Anxiety was more highly correlated with credit misuse $(r=.27)$ compared to 
Table 1. Means, Standard Deviations, and Correlations of Variables

\begin{tabular}{|c|c|c|c|c|c|c|c|c|}
\hline & \multirow{2}{*}{$M$} & \multirow{2}{*}{$S D$} & \multicolumn{6}{|c|}{ Pearson correlation coefficients $(N=1146)$} \\
\hline & & & 1 & 2 & 3 & 4 & 5 & 6 \\
\hline 1. Time preference & 2.93 & 1.20 & 1 & & & & & \\
\hline 2. Goal attainment expectation & 1.36 & .60 & $-.08^{*}$ & 1 & & & & \\
\hline 3. Unrealistic optimism & 2.47 & 1.13 & $-.08^{* *}$ & -.02 & 1 & & & \\
\hline 4. Overconfidence & -1.34 & 1.06 & -.04 & $-.09^{*}$ & $.16 "$ & 1 & & \\
\hline 5. Anxiety & 2.63 & .82 & .05 & $.16^{*}$ & $-.11^{\prime \prime}$ & -.03 & 1 & \\
\hline 6. Credit misuse & 1.41 & .62 & -.01 & $.11^{*}$ & $.09^{*}$ & $.20^{* *}$ & $.27^{*}$ & 1 \\
\hline
\end{tabular}

$p<.01,{ }^{*} p<.05$

Table 2. Descriptive Statistics and Frequency of Credit Misuse Items

\begin{tabular}{|c|c|c|c|c|c|c|}
\hline Credit misuse items & Mean $(S D)$ & Never & Rarely & Sometimes & Often & Very often \\
\hline 1. Took cash advance from credit & $1.24(.67)$ & $86.2 \%$ & $6.3 \%$ & $4.8 \%$ & $1.8 \%$ & $0.5 \%$ \\
\hline 2. Used payday loan service & $1.16(.59)$ & $90.7 \%$ & $4.1 \%$ & $3.0 \%$ & $1.4 \%$ & $0.5 \%$ \\
\hline 3. Maxed out credit card limit & $1.60(1.08)$ & $70.0 \%$ & $12.1 \%$ & $8.7 \%$ & $6.0 \%$ & $3.1 \%$ \\
\hline 4. Paid credit card bill on time each month & $4.37(1.09)$ & $4.8 \%$ & $3.0 \%$ & $9.8 \%$ & $25.0 \%$ & $67.4 \%$ \\
\hline
\end{tabular}

Note: The forth item (paid credit card bill on time each month) was reverse-coded to construct the credit misuse scale.

the cognitive bias factors. The results showed that although both cognitive bias factors and anxiety were suggestive of biased financial behavior, the associations were not all in the same direction.

\section{Regression Analyses}

The statistically significant results of hierarchical multiple regression analyses are presented in Table 3. The control variables (gender, SES, GPA), added to the model in the first step, showed that being male and having a lower GPA were significantly associated with more credit misuse.

In the second step, the four cognitive bias factors were added to the model. The regression results showed that students with a delayed goal attainment expectation regarding financial independence $(\beta=.97, p<.01)$, more unrealistic optimism regarding their future income $(\beta=$. $67, p<.05)$, and those who were overconfident about their financial knowledge $(\beta=.16, p<.01)$ engaged in more credit misuse. These results provided support for hypotheses H2 (goal attainment expectation), H3 (unrealistic optimism) and H4 (overconfidence). However, we found no support for $\mathrm{H} 1$ that present-oriented time preference would be significantly related to credit misuse. Adding cognitive bias factors to the model significantly increased the accounted variance (change in $\left.R^{2}=.043, p<.01\right)$.

In the third step, anxiety was added to the model and showed that students with higher levels of anxiety engaged in more credit misuse $(\beta=.25, p<.01)$, thus providing support for H5. Moreover, there was a significant increase in the amount of variance explained for credit misuse (change in $R^{2}=.058, p<.01$ ). These results provided support that cognitive bias and anxiety were associated with credit misuse.

\section{Moderator Analyses}

To determine whether certain cognitive bias factors interacted with anxiety to affect credit misuse, we reestimated the three-step model, standardizing the predictor variables and added the interaction terms in the fourth step of the model (Table 4). The main effects of the cognitive bias factors and anxiety were replicated in this four-step model. The results indicated that two of the interaction terms moderated the association with credit misuse: the combination of present-oriented time preference and 
Family and Environment Research

Table 3. Results of Regression on Credit Misuse

\begin{tabular}{lllll}
\hline \multicolumn{1}{c}{ Variable } & $\boldsymbol{B}$ & $\beta$ & $\boldsymbol{R}^{2}$ & $\boldsymbol{\Delta \boldsymbol { R } ^ { 2 }}$ \\
\hline Step1: Control variables & & & & \\
Gender (Female) & $-.09^{*}$ & -.07 & & \\
SES & -.01 & -.01 & & \\
GPA & $-.17^{* *}$ & -.16 & .052 & $.052^{*}$ \\
Step2: Cognitive bias & & & & \\
Time preference & -.01 & -.03 & & \\
Goal attainment expectation & $.10^{* *}$ & .10 & & \\
Unrealistic optimism & $.03^{*}$ & .07 & & \\
Overconfidence & $.09^{* *}$ & .16 & .095 & $.043^{* *}$ \\
Step3: Negative mood-state & & & & \\
Anxiety & $.18^{* *}$ & .25 & .152 & $.058^{*}$ \\
\hline
\end{tabular}

$p<.01, p<.05$

Table 4. Moderating Effect of Anxiety in the Association between Cognitive Bias and Credit Misuse

\begin{tabular}{|c|c|c|c|}
\hline Variable & $B$ & $R^{2}$ & $\Delta R^{2}$ \\
\hline \multicolumn{4}{|l|}{ Step1: Control variables } \\
\hline Gender & $-.06^{*}$ & & \\
\hline SES & -.02 & & \\
\hline GPA & $-.15^{\prime \prime}$ & .052 & $.052^{* *}$ \\
\hline \multicolumn{4}{|l|}{ Step2: Cognitive bias } \\
\hline Time preference & -.02 & & \\
\hline Goal attainment expectation & $.09^{* *}$ & & \\
\hline Unrealistic optimism & $.07^{*}$ & & \\
\hline Overconfidence & $.15^{*}$ & .095 & $.043^{*}$ \\
\hline \multicolumn{4}{|l|}{ Step3: Negative mood-state } \\
\hline Anxiety & $.23^{* *}$ & .152 & $.058^{* \prime}$ \\
\hline \multicolumn{4}{|l|}{ Step4: Interactions } \\
\hline Time preference $x$ Anxiety & $-.06^{*}$ & & \\
\hline $\begin{array}{l}\text { Goal attainment expectation x } \\
\text { Anxiety }\end{array}$ & .03 & & \\
\hline Unrealistic optimism x Anxiety & $.07^{*}$ & & \\
\hline Overconfidence $x$ Anxiety & .06 & .169 & $.017^{*}$ \\
\hline
\end{tabular}

Note: Unstandardized regression coefficients $(B)$ are reported because standardized coefficients are inappropriate with interaction terms (see Aiken and West, 1991); All variables were standardized with Z-score (except for gender: effective coding)

$p<.01, p<.05$

anxiety, and the combination of unrealistic optimism regarding future income and anxiety. The addition of the interaction terms significantly contributed to the total

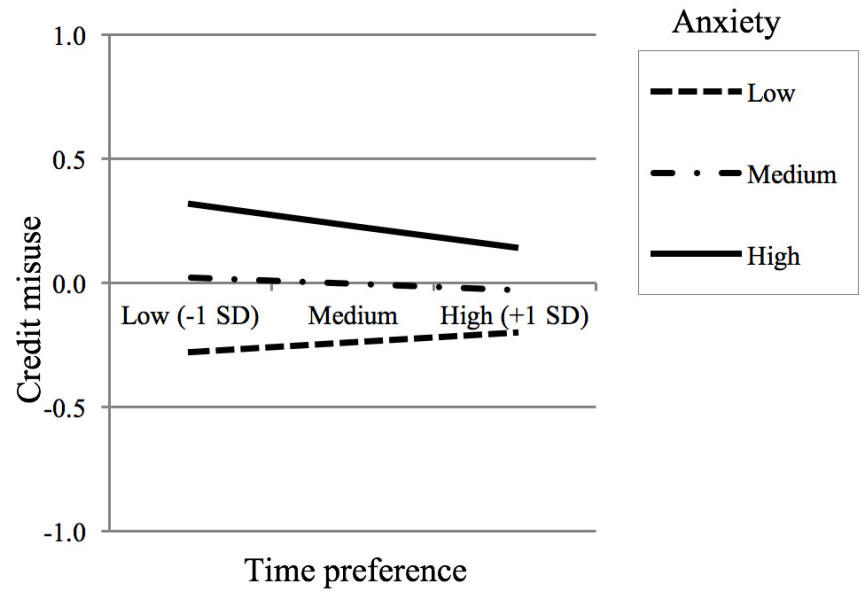

Figure 1. The Moderating Effect of Anxiety on the Relationship between Time Preference and Credit Misuse.

Note: Values shown are standardized effects.

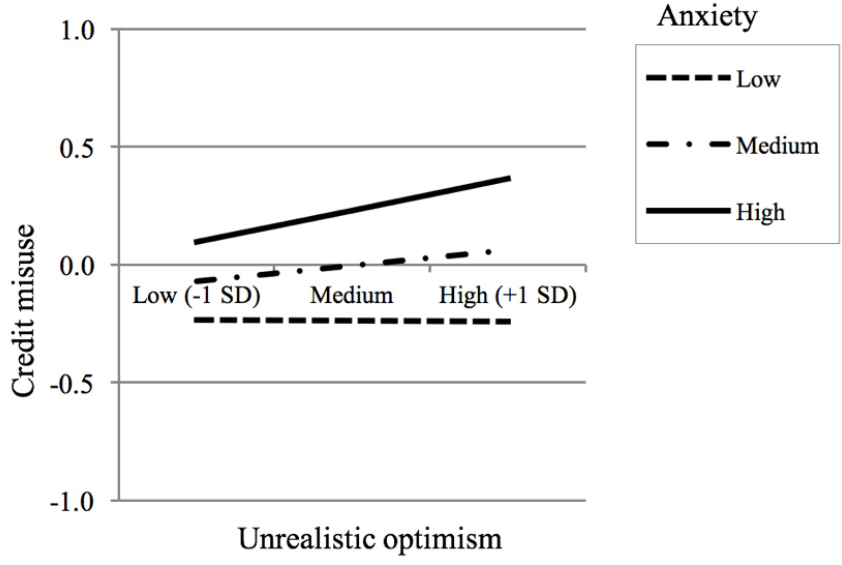

Figure 2. The Moderating Effect of Anxiety on the Relationship between Unrealistic Optimism and Credit Misuse.

Note: Values shown are standardized effects.

variance explained (change of $R^{2}=.017, p<.01$ ). Thus, after controlling for gender, SES, and GPA, and taking into account the main effects of cognitive bias and anxiety, the interactions between cognition and anxiety contributed to credit misuse, providing partial support for $\mathrm{H6}$.

The first interaction result revealed that the relationship between present-oriented time preference and credit misuse was moderated by anxiety $(B=-.063, p<.05)$, despite the non-significant main effect of time preference. We graphically depicted the significant interaction (Figure 1), using the standardized regression coefficients of the regression lines for high (1 SD above the mean) and low 
(1 SD below the mean) present-oriented time preference on anxiety. The result shows that present-oriented time preference significantly decreased credit misuse when the level of anxiety was high $(B=.087, p<.05)$, opposite the direction proposed in $\mathrm{H} 1$.

The second significant interaction between unrealistic optimism and anxiety associated with credit misuse $(B=.069$, $p<$.05) is depicted in Figure 2. The interaction effect showed that the greater the unrealistic optimism regarding future income, the more credit misuses for students with higher anxiety level $(B=.135, p<.01)$.

\section{Discussion}

Using a behavioral economics perspective, we examined the role of cognitive bias and anxiety as potential triggers for credit misuse among college students. We considered four specific cognitive bias factors (i.e., time preference, goal attainment expectation, unrealistic optimism, and overconfidence) and found that all but one (time preference) were directly and positively associated with credit misuse. We also considered the role of financial anxiety and found that, after accounting for the cognitive bias factors, the positive association between financial anxiety and credit misuse was significant and stronger than the combined effect of the cognitive bias factors. Finally, we found that cognition and anxiety interacted to affect credit misuse, sometimes in unexpected ways. A further discussion of these findings follows.

\section{Direct Main Effects of Cognitive Bias}

We examined cognitive bias as a potential contributor to credit misuse, conceptualized as a type of irrational decision-making. The results provided support that: 1) delayed expectation (longer anticipated time) to achieve financial independence, 2) over-optimism about future income, and 3) overconfidence in financial knowledge were associated with more credit misuses.

Delayed expectations in achieving financial independence might reflect the thirty-year trend of young adults taking a longer time to transition to adulthood (Settersten, 2012), and this delayed expectation might now be considered normative. In the context of lingering employment instability, students may not realize that salaries have stagnated in many occupations while employee-costs of employment benefits have increased (Littrell et al., 2010). This might contribute to students' unrealistic optimism toward their future income. Finally, students' financial knowledge is typically based on limited experience, constrained financial demands, and high levels of parental support; all of these may impact their ability to accurately gauge their financial knowledge or understand the implications of their financial choices. This will likely change once they graduate, pay more of their own bills and dayto-day expenses, including student loans.

Although studies have demonstrated that present bias is associated with credit card debt (e.g., Lea, Webley, \& Walker, 1995; Meier \& Sprenger, 2010), we did not find support for a main effect of present-oriented time preference. We speculate that credit card use at this point may be seen as a convenience in paying for things, rather than a borrowing behavior. It is also possible that some students have limited resources and must resort to borrowing. Future studies should consider the impact of time preference on multiple types of financial behaviors to see if these associations differ.

\section{Direct Main Effect of Anxiety}

Our results showed that a higher level of anxiety was associated with credit misuse, and the effect was stronger than that of all cognitive bias factors combined. This suggests that mood-state may contribute to credit misuse. Consumption (especially unplanned consumption) can be viewed as a form of emotion regulation such that consumers engage in shopping as a way to alleviate negative mood (Kemp \& Kopp, 2011). From this perspective, it makes sense that students experiencing financial anxiety may engage in credit misuse as a strategy for immediate down-regulation of negative mood and up-regulation of positive mood. 
Since the present study relied on cross-sectional data, however, it is not possible to rule out the temporal primacy of the association between anxiety and credit misuse. Those students burdened with more debt including student loan or credit card debt are more likely to have higher anxiety (Archuleta, Dale \& Spann, 2013). Thus, it is plausible that anxiety reflects the effects of students past credit misuse or simply that financially fragile students are more anxious because they must resort to borrowing. Future research is needed to disentangle this association.

\section{Combined Effects}

This study also revealed significant interactions between cognitive bias factors and anxiety. The relationship between unrealistic optimism toward future income and credit misuse suggests that anxiety may exacerbate the impact of unrealistic optimism on credit misuse. Our findings imply that, while unrealistic optimism may serve as a coping strategy to reduce anxiety, it may encourage an individual to engage more frequently in credit misuse. Hence, whereas unrealistic optimism among young adults may be an adaptive coping strategy in the short term, it could play out as a maladaptive one in the long term if they engage in credit misuse.

Despite the lack of a direct effect, present-oriented time preference was negatively associated with credit misuse when combined with higher levels of anxiety opposite the direction proposed in H1. Our results suggest that time preference per se may not be directly related to credit misuse, but instead interact with anxiety to magnify concerns about present finances. Our hypothesis was based on empirical studies demonstrating a positive association, such that higher anxiety levels increased risky or irrational behavior (Leith \& Baumeister, 1996). An alternate explanation, however, may be that that high-anxious people may feel insecure or uncertain about the future and therefore choose less-risky options (e.g., Gambetti \& Giusberti 2012; Hockey et al., 2000). Gambetti and Giusberti (2012) found that anxious people were more sensitive to immediate decision-making. In a similar vein, Haselton,
Nettle \& Andrews (2005) explained anxiety as a protective bias that works as a psychological defense mechanism, one that will often incorrectly perceive danger and avoid the possible threats. Because many students may be feeling insecure about their future, they may be keenly aware of their present financial obligations and thus avoid taking on additional debt, even though they prefer immediate gratification. Weighing personal needs (i.e., financial demands) against wants (i.e., dinner with friends) could account for the interaction. The student might conclude, for example: "I need to pay for my graduation fees next month, so I cannot go out to dinner with my friends". Exploration of these associations is an area for further research.

\section{Limitations}

While the results of our study provide several useful insights, there are limitations to consider. For one, this is the first study to simultaneously consider the role of both cognitive bias factors and anxiety on college students borrowing behavior, and thus the findings should be considered exploratory. We used data collected in 2010, so the credit misuse results may not reflect today's economic situation or college students' attitude. Thus, additional research is needed to further substantiate, or refute these results with recent data. In addition, many of our measures rely on single-item responses and the findings must be interpreted cautiously (Diamantopoulos et al., 2012). Given the life stage of the respondents, a single-item question to measure students' time preference may fail to capture their actual dispositional time preference. Future studies could examine these associations using more robust measures. Another limitation is our measurement of overconfidence as the difference between subjective knowledge and objective knowledge using separate scales and different items. A percentage-based subjective knowledge measurement (e.g., rated confidence on the objective financial knowledge questions rage from $50 \%$ to $100 \%$ ) might provide a more accurate calibration of overconfidence, one using an objective probability (i.e., percent correct) or a subjective probability (i.e., rated confidence) (see Alba \& Hutchinson, 
2000). Finally, our study focused on anxiety, but several negative mood-states warrant investigation in association with credit misuse, including depression (e.g., Pietromonaco \& Rook 1987), anger (e.g., Gambetti \& Giusberti 2012) and fatigue (e.g., Hockey et al., 2000).

\section{Implications and Conclusion}

Despite these limitations, the study offers unique insights for those who are concerned about students' financial well-being. First, improving financial knowledge alone will not necessarily lead to better financial decisions because cognitive bias and mood affect students' borrowing behaviors. Because students have limited experience with debt, they are likely to discount consequences or underestimate their ability to repay it. Parents and educators can guide students by engaging them in conversations about borrowing as a loan against their future. Specific discussion topics include differentiating the risks associated with types of borrowing (e.g., paying for education expenses with credit card versus student loan), the implications of borrowing for college but not graduating, and the importance of investigating all options to financing their education (e.g., negotiating for financial aid, work study, scholarships).

Second, parents, practitioners, and those in student support services can emphasize that prudent financial decision-making includes awareness of cognitive and emotional factors. Teaching students to recognize the factors that interfere with responsible financial choices and providing them with strategies for managing multiple financial demands may help them avoid risky choices. For example, providing students with strategies (e.g., monitoring expenses, living within budget, putting some money aside for emergencies; budgeting an amount for socializing) when explaining that solving current problems (e.g., unexpected expense) with short-term fixes (credit card advance) may actually increase anxiety. Finally, college administrators who are entrusted with the success of students can provide ongoing access to information about how to manage credit wisely, where to find financial assistance, and available resources to offset education costs.

\section{Declaration of Conflicting Interests}

The authors declared no conflicts of interest with respect to their authorship or publication of this article.

\section{Acknowledgments}

This research uses data from the Arizona Pathways to Life Success for University Students Project (APLUS), directed by Joyce Serido at the University of Minnesota-Twin Cities and designed by Soyeon Shim at the University of Wisconsin-Madison \& Joyce Serido. Information on how to obtain access to the APLUS data files is available on the APLUS website https://www.aplushappiness.org/

Data collection was funded by the National Endowment for Financial Education, Citi Foundation, and the Take Charge America Institute.

\section{References}

Aiken, L. S., \& West, S. G. (1991). Multiple regression: Testing and interpreting interactions. Newbury Park, CA: Sage.

Alba, J. W., \& Hutchinson, J. W. (2000). Knowledge calibration: What consumers know and what they think they know. Journal of Consumer Research, 27(2), 123-156. https://doi.org/10.1086/314317

Archuleta, K. L., Dale, A., \& Spann, S. M. (2013). College students and financial distress: Exploring debt, financial satisfaction, and financial anxiety. Journal of Financial Counseling and Planning, 24(2), 50-62.

Arnett, J. J. (2004). Emerging adulthood: The winding road from the late teens through the twenties. New York, NY: Oxford University Press.

Barber, B., Eccles, J., \&t Stone, M. (2001). Whatever happened to the jock, the brain, and the princess? Young adult pathways linked to adolescent activity involvement and social identity. Journal of Adolescent Research, 16(5), 429-455. https://doi. org/10.1177/0743558401165002

Barlow, D. H. (2002). Anxiety and its disorders: The nature and treatment of anxiety and panic (2nd ed.). New York, NY: The Guilford Press.

Barnett, R. C., Garies, K. C., James, J. B., \&t Steele, J. (2003). Planning ahead: College seniors' concerns about career-marriage conflict. 
Family and Environment Research

Journal of Vocational Behavior, 62(2), 305-319. https://doi. org/10.1016/S0001-8791(02)00028-3

Baron, R. M., \&t Kenny, D. A. (1986). The moderator-mediator variable distinction in social psychological research: Conceptual, strategic, and statistical considerations. Journal of Personality \& Social Psychology, 51(6), 1173-1182. https://doi.org/10.1037//0022-3514.51.6.1173

Bishop, S. J. (2008). Trait anxiety and impoverished prefrontal control of attention. Nature Neuroscience, 12(1), 92-98. https://doi.org/10.1038/ nn.2242

Camerer, C. F., Issacharoff, S., Loewenstein, G. F., O'Donoghue, T., \&t Rabin, M. (2003). Regulation for conservatives: Behavioral economics and the case for 'asymmetric paternalism'. Law Review, 151(3), 12111254. https://doi.org/10.2307/3312889

Coleman, R. P. (1983). The continuing significance of social class to marketing. Journal of Consumer Research, 10(3), 265-280. https://doi. org/10.1086/208966

Davies, E., \&t Lea, S. E. G. (1995). Student attitudes to student debt. Journal of Economic Psychology, 16(4), 663-679. https://doi. org/10.1016/0167-4870(96)80014-6

Diamantopoulos, A., Sarstedt, M., Fuchs, C., Kaiser, S., \&t Wilczynski, P. (2012). Guidelines for choosing between multi-item and single-item scales for construct measurement: A predictive validity perspective. Journal of the Academy of Marketing Science, 40(3), 434-449. https:// doi.org/10.1007/s11747-011-0300-3

Dunegan, K. J., Duchon, D., \&t Barton, S. L. (1992). Affect, risk, and decision criticality: Replication and extension in a business setting. Organizational Behavior and Human Decision Processes, 53(3), 335351. https://doi.org/10.1016/0749-5978(92)90069-J

Finke, M. S., \&t Huston, S. J. (2003). Factors affecting the probability of choosing a risky diet. Journal of Family and Economic Issues, 24(3), 291-303. https://doi.org/10.1023/A:1025499322428

Frederick, S., Loewenstein, G., \& O'donoghue, T. (2002). Time discounting and time preference: A critical review. Journal of Economic Literature, 40(2), 351-401. https://doi.org/10.1257/002205102320161311

Exler, F., Livshits, I., MacGee, J., \& Tertilt, M. (2018). Regulating consumer credit with over-optimistic borrowers. Society for Economic Dynamics. Retrieved Sep 15, 2018, from https://economicdynamics. org/meetpapers/2018/paper_1064.pdf

Gambetti, E., \& Giusberti, F. (2012). The effect of anger and anxiety traits on investment decisions. Journal of Economic Psychology, 33(6), 1059-1069. https://doi.org/10.1016/j.joep.2012.07.001

Gervais, S., Heaton, J., \& Odean, T. (2002). The positive role of overconfidence and optimism in investment policy. University of Pennsylvania. Retrieved Jan 15, 2018, from http://citeseerx.ist.psu. edu/viewdoc/download?doi=10.1.1.195.7755\&rep=rep1\&type=pdf

Gray, J. R., Braver, T. S., \& Raichle, M. E. (2002). Integration of emotion and cognition in the lateral prefrontal cortex. Proceedings of the National Academy of the Sciences, 99(6), 4115-4120. https://doi. org/10.1073/pnas.062381899

Gudmunson, C. G., \&t Danes, S. M. (2011). Family financial socialization: Theory and critical review. Journal of Family and Economic Issues, 32(4), 644-667. https://doi.org/10.1007/s10834-011-9275-y

Haselton, M. G., Nettle, D., \& Andrews, P. W. (2005). The evolution of cognitive bias. In D. M. Buss (Ed.), The handbook of evolutionary psychology (pp. 724-746). Hoboken, NJ: Wiley and Sons.

Hilgert, M. A., Hogarth, J. M., \&t Beverly, S. G. (2003). Household financial management: The connection between knowledge and behavior. Federal Reserve Bulletin, 89(30), 9-22.

Hirshleifer, D. (2008). Psychological bias as a driver of financial regulation. European Financial Management, 14(5), 856-874. https:// doi.org/10.1111/j.1468-036X.2007.00437.x

Hockey, G. R. J., Maule, A. J., Clough, P. J., \&t Bdzola, L. (2000). Effects of negative mood states on risk in everyday decision making. Cognition \& Emotion, 14(6), 823-855. https://doi. org/10.1080/02699930050156654

Houle, J. N. (2014). Disparities in debt: Parents' socioeconomic resources and young adult student loan debt. Sociology of Education, 87(1), 53-69. https://doi.org/10.1177/0038040713512213

Isen, A. M., \& Means, B. (1983). The influence of positive affect on decision-making strategy. Social Cognition, 2(1), 18-31. https://doi. org/10.1521/soco.1983.2.1.18

Isen, A. M., \& Patrick, R. (1983). The effects of positive feelings on risk taking: When the chips are down. Organizational Behavior and Human Performance, 31(2), 194-202. https://doi.org/10.1016/00305073(83)90120-4

Jaccard, J., \&t Turrisi, R. (2003). Interaction effects in multiple regression (No. 72). Thousand Oaks, CA: Sage Publications.

Jones, G. (1995). More than just a game: Research developments and issues in competitive anxiety in sport British Journal of Psychology, 86(4), 449-478. https://doi.org/10.1111/j.2044-8295.1995.tb02565.x

Jones, G., \& Hanton, S. (1996). Interpretation of competitive anxiety symptoms and goal attainment expectancies. Journal of Sport Et Exercise Psychology, 18(2), 144-157. https://doi.org/10.1123/ jsep.18.2.144

Kemp, E., \& Kopp, S. W. (2011). Emotion regulation consumption: When feeling better is the aim. Journal of Consumer Behaviour, 10(1), 1-7. https://doi.org/10.1002/cb.341

Lea, S. E. G., Webley, P., \&t Walker, C. M. (1995). Psychological factors in consumer debt: Money management, economic socialization, and credit use. Journal of Economic Psychology, 16(4), 681-701. https:// doi.org/10.1016/0167-4870(95)00013-4

Leith, K. P., \&t Baumeister, R. F. (1996). Why do bad moods increase self- 
defeating behavior? Emotion, risk tasking and self-regulation. Journal of Personality and Social Psychology, 71(6), 1250-1267. https://doi. org/10.1037/0022-3514.71.6.1250

Limbu, Y. B. (2017). Credit card knowledge, social motivation, and credit card misuse among college students: Examining the informationmotivation-behavioral skills model. International Journal of Bank Marketing, 35(5), 842-856. https://doi.org/10.1108/IJBM-04-20160045

Littrell, J., Brooks, F., Ivery, J. M., \&t Ohmer, M. L. (2010). Why you should care about the threatened middle class. Journal of Sociology and Social Welfare, 37(2), 87-113.

Lusardi, A. (1998). On the importance of the precautionary saving motive. The American Economic Review, 88(2), 449-453.

Lusardi, A, Mitchell, O. S., \&t Curto, V. (2010). Financial literacy among the young. Journal of Consumer Affairs, 44(2), 358-380. https://doi. org/10.1111/j.1745-6606.2010.01173.x

Lyons, A. C. (2004). A profile of financially at-risk college students. Journal of Consumer Affairs, 38(1), 56-80. https://doi.org/10.1111/ j.1745-6606.2004.tb00465.x

Lyons, A. C., Rachlis, M., \&t Scherpf, E. (2007). What's in a score? Differences in consumers' credit knowledge using OLS and quantile regressions. The Journal of Consumer Affairs, 41(2), 223-249. https:// doi.org/10.1111/j.1745-6606.2007.00079.x

Lyons, A. C. (2008). Risky credit card behavior of college students. In J. J. Xiao (Ed.), Advances in consumer financial behavior research (pp. 185-207). New York, NY: Springer Publishing Company.

Ma, J., \& Baum, S. (2016). Trends in community colleges: Enrollment, prices, student debt, and completion. College Board Research. Retrieved Sep 15, 2018, from https://trends.collegeboard.org/sites/ default/files/trends-in-community-colleges-research-brief.pdf

Meier, S., \& Sprenger, C. (2010). Present-biased preferences and credit card borrowing. American Economic Journal: Applied Ecoomics, 2(1), 193-210. https://doi.org/10.1257/app.2.1.193

Mulder, C. H., \& Clark, W. A. V. (2002). Leaving home for college and gaining independence. Environment and Planning, 34(6), 981-999. https://doi.org/10.1068/a34149

Museus, S. D. (2010). Understanding racial differences in the effects of loans on degree attainment: A path analysis. Journal of College Student Retention, 11(4), 499-527. https://doi.org/10.2190/CS.11.4.d

Norvilitis, J. M., Merwin, M. M., Osberg, T. M., Roehling, P. V., Young, P., \& Kamas, M. M. (2006). Personality factors, money attitudes, financial knowledge and credit card debt in college students. Journal of Applied Social Psychology, 36(6), 1395-1413. https://doi.org/10.1111/ j.0021-9029.2006.00065.x

O'Donoghue, T., \& Rabin, M. (2001a). Choice and procrastination. Quarterly Journal of Economics, 116(1), 121-160. https://doi. org/10.1162/003355301556365

O'Donoghue, T., \& Rabin, M. (2001b). Risky behavior among youths: Some issues from behavioral economics. In J. Gruber (Ed.), Youthful risky behavior: An economic perspective (pp. 29-67). Chicago, IL: University of Chicago Press.

Palan, K. M., Morrow, P. C., Trapp, A., \&t Blackburn, V. (2011). Compulsive buying behavior in college students: The mediating role of credit card misuse. Journal of Marketing Theory and Practice, 19(1), 81-96. https://doi.org/10.2753/MTP1069-6679190105

Peach, N. D., \&t Yuan, H. (2017). Assessing the financial knowledge, behaviours, and attitudes of undergraduates. e-Journal of Business Education and Scholarship of Teaching, 11(2), 27-38.

Perry, V. G. (2008). Is ignorance bliss? Consumer accuracy in judgments about credit ratings. The Journal of Consumer Affairs, 42(2), 189-205. https://doi.org/10.1111/j.1745-6606.2008.00104.x

Pietromonaco, P. R., \& Rook, K. S. (1987). Decision style in depression: The contribution of perceived risk versus benefits. Journal of Personality and Social Psychology, 52(2), 399-408. http://dx.doi. org/10.1037/0022-3514.52.2.399

Price, D. V., \& Davis, R. J. (2006). Institutional grants and baccalaureate degree attainment. Washington, DC: National Association of Student Financial Aid Administrators.

Price, P. C. (2000). Unrealistic optimism in the prediction of competitive outcomes. Thinking and Reasoning, 6(2), 161-172.

Robb, C. A., \& Pinto, M. B. (2010). College students and credit card use: An analysis of financially at-risk of students. College Student Journal, 44(4), 823-835.

Seaward, H. G. W., \&t Kemp, S. (2000). Optimism bias and student debt. New Zealand Journal of Psychology, 29(1), 17-19.

Settersten, R. A. (2012). The contemporary context of young adulthood in the USA: From demography to development, from private troubles to public issues. In A. Booth et al. (Eds.) Early adulthood in a family context (pp. 3-26). New York, NY: Springer.

Shierholz, H., Sabadish, N., \& Finio, N. (2013). The class of 2013: Young graduates still face dim job prospects. Washington, DC: Economic Policy Institute.

Shim, S., Barber, B. L., Card, N. A., Xiao, J. J., \&t Serido, J. (2010). Financial socialization of first-year college students: The roles of parents, work, and education. Journal of Youth and Adolescence, 39(12), 1457-1470. http://dx.doi.org/10.1007/s10964-009-9432-x

Simon, H. A. (1972). Theories of bounded rationality. Decision and Organization, 1(1), 161-176.

Smith, T. E., Richards, K. V., Shelton, V. M., \&t Malespin, T. S. (2015). Sirens' call: Understanding poor financial decision making and credit card misuse. Journal of Human Behavior in the Social Environment, 25(8), 897-906. https://doi.org/10.1080/10911359.2015.1039156 
Stein, C. H., Hoffmann, E., Bonar, E. E., Leith, J. E., Abraham, K. M., Hamill, A. C., et al. (2013). The United States economic crisis: Young adults' reports of economic pressures, financial and religious coping and psychological well-being. Journal of Family and Economic Issues, 34(2), 200-210. https://doi.org/10.1007/s10834-012-9328-x

Sunstein, C. R. (2006). Boundedly rational borrowing. University of Chicago Law Review, 73, 249-270.

Sweet, E., Nandi, A., Adam, E. K., \& McDade, T. W. (2013). The high price of debt: Household financial debt and its impact on mental and physical health. Social Science and Medicine, 91, 94-100. https://doi. org/10.1016/j.socscimed.2013.05.009

Tokar Asaad, C. (2015). Financial literacy and financial behavior: Assessing knowledge and confidence. Financial Services Review, 24(2), 101-117.

Vlaev, I., \& Elliott, A. (2013). Financial well-being components. Social
Indicators Research, 118(3), 1103-1123. https://doi.org/10.1007/ s11205-013-0462-0

Weinstein, N. D. (1980). Unrealistic optimism about future life events. Journal of Personality and Social Psychology, 39(5), 806-820. http:// dx.doi.org/10.1037/0022-3514.39.5.806

Wilkinson, N. (2008). An introduction to behavioral economics. New York, NY: Palgrave Macmillan.

Xiao, J. J., Tang, C., Serido, J., \& Shim, S. (2011). Antecedents and consequences of risky credit behavior among college students: Application and extension of the theory of planned behavior. Journal of Public Policy \&t Marketing, 30(2), 239-245. https://doi.org/10.1509/ jppm.30.2.239

Yang, E., \&t Gysbers, N. C. (2007). Career transitions of college seniors. The Career Development Quarterly, 56(2), 157-170. https://doi. org/10.1002/j.2161-0045.2007.tb00028.x 